\title{
The main pulmonary artery in adults: a controlled multicenter study with assessment of echocardiographic reference values, and the frequency of dilatation and aneurysm in Marfan syndrome
}

Sara Sheikhzadeh ${ }^{1 \dagger}$, Julie De Backer ${ }^{4 \dagger}$, Neda Rahimian Gorgan ${ }^{1}$, Meike Rybczynski ${ }^{1}$, Mathias Hillebrand ${ }^{1}$, Helke Schüler ${ }^{1}$, Alexander M Bernhardt', Dietmar Koschyk ${ }^{1}$, Peter Bannas ${ }^{2}$, Britta Keyser $^{5}$, Kai Mortensen ${ }^{6}$, Robert M Radke ${ }^{7}$, Thomas S Mir ${ }^{1}$, Tilo Kölbel ${ }^{1}$, Peter N Robinson ${ }^{8}$, Jörg Schmidtke ${ }^{5}$, Jürgen Berger ${ }^{3}$, Stefan Blankenberg ${ }^{1}$ and Yskert von Kodolitsch ${ }^{1 *}$

\begin{abstract}
Background: Echocardiographic upper normal limits of both main pulmonary artery (MPA) diameters (MPA-d) and ratio of MPA to aortic root diameter (MPA-r) are not defined in healthy adults. Accordingly, frequency of MPA dilatation based on echocardiography remains to be assessed in adults with Marfan syndrome (MFS).

Methods: We enrolled 123 normal adults (72 men, 52 women aged $42 \pm 14$ years) and 98 patients with MFS (42 men, 56 women aged $39 \pm 14$ years) in a retrospective cross-sectional observational controlled study in four tertiary care centers. We defined outcome measures including upper normal limits of MPA-d and MPA-r as 95 quantile of normal persons, MPA dilatation as diameters > upper normal limits, MPA aneurysm as diameters $>4 \mathrm{~cm}$, and indication for surgery as MPA diameters $>6 \mathrm{~cm}$.

Results: MPA diameters revealed normal distribution without correlation to age, sex, body weight, body height, body mass index and body surface area. The upper normal limit was $2.6 \mathrm{~cm}$ (95\% confidence interval $(\mathrm{Cl})=2.44-2.76 \mathrm{~cm})$ for MPA-d, and 1.05 (95\% Cl=.86-1.24) for MPA-r. MPA dilatation presented in 6 normal persons (4.9\%) and in 68 MFS patients (69.4\%; $P<.001)$, MPA aneurysm presented only in MFS (15 patients; 15.3\%; $P<.001$ ), and no patient required surgery. Mean MPA-r were increased in MFS $(P<.001)$, but ratios $>1.05$ were equally frequent in 7 normal persons $(5 \%)$ and in 8 MFS patients $(10.5 \% ; P=.161)$. MPA-r related to aortic root diameters $(P=.042)$, reduced left ventricular ejection fraction $(P=.006)$, and increased pulmonary artery systolic pressures $(P=.040)$. No clinical manifestations of MFS and no FBN1 mutation characteristics related to MPA diameters.

Conclusions: We established $2.6 \mathrm{~cm}$ for MPA-d and 1.05 for MPA-r as upper normal limits. MFS exhibits a high prevalence of MPA dilatation and aneurysm. However, patients may require MPA surgery only in scarce circumstances, most likely because formation of marked MPA aneurysm may require LV dysfunction and increased PASP.
\end{abstract}

Keywords: Pulmonary artery, Marfan syndrome, FBN1, Echocardiography, Reference values

\footnotetext{
*Correspondence: kodolitsch@uke.de

${ }^{\dagger}$ Equal contributors

${ }^{1}$ Centre of Cardiology and Cardiovascular Surgery, University Medical Center

Hamburg-Eppendorf, Martinistraße 52, 20246 Hamburg, Germany

Full list of author information is available at the end of the article
} 


\section{Background}

The old Ghent nosology considered dilatation of the main pulmonary artery (MPA) as a diagnostic criterion of Marfan syndrome (MFS) [1] but data on the prevalence of MPA dilatation or aneurysm remained both scarce and conflicting in MFS [2-5]. Most likely, little attention has been paid to MPA because cardiovascular complications of MFS usually result only from rupture or dissection of the aortic root [6] or from ventricular arrhythmia [7,8]. Moreover, cardiovascular criteria of MFS are usually assessed with transthoracic echocardiography, but in adults upper normal limits of diameters of the MPA (MPA-d) remain to be defined on echocardiography [9]. As a consequence, there is no current data on the echocardiographic prevalence of MPA dilatation in MFS patients, and for this reason the revised Ghent nosology removed MPA dilatation from the list of diagnostic criteria [9]. Some case reports highlight that MPA dilatation may lead to severe complications in MFS [10], and current magnetic resonance imaging (MRI) and computed tomography (CT) studies suggest that pathology of the MPA is frequent in MFS [3-5,11,12]. Hence, echocardiographic examination of the MPA may be important in the evaluation of adults with MFS to further elucidate the diagnostic and prognostic implications of MPA dilatation.

Dilatation of the MPA is present with MPA-d above upper normal limits, where CT and MRI studies identified diameters between $2.8 \mathrm{~cm}$ and $3.2 \mathrm{~cm}$ as upper limits [4,13-15]. Moreover, the MPA ratio (MPA-r) is defined as a ratio of MPA-d to aortic root diameter [14]. Usually, the diameter of MPA equals the size of the proximal aorta, and hence CT or MRI studies of pulmonary hypertension $(\mathrm{PH})$ identify ratios $>1$ as a marker of MPA dilatation [14,16-19]. The largest study of reference values of MPA is the Framingham study which used non-contrast cardiac CT in 706 normal adults. This study established $2.9 \mathrm{~cm}$ in men and $2.7 \mathrm{~cm}$ in women as sex-specific normative reference values for MPA-d and 0.9 for MPA-r [14]. Aneurysms of MPA are defined with MPA-d $>4 \mathrm{~cm}[20,21]$. Such aneurysms are reported in 1 of 14,000 autopsies [22]. Criteria for surgery of MPA aneurysms are not firmly established, but surgeons agree to operate upon in most patients with symptomatic MPA aneurysms or in aneurysms with MPA-d >6 cm [20,21,23].

Normative MPA-d and MRA-r values on CT and MRI do not apply to transthoracic echocardiography for various reasons. First, echocardiographic MPA-d and aortic root diameters are measured at other sites of the vessel than on CT or MRI, which may infer substantial differences of measurements because of the asymmetric anatomy of both MPA and the aortic root [2,5,24]. Second, measurements on CT and MRI are usually obtained as outer diameters of the vessel rather than with the leading-edge method [24-26]. Third, compared to CT and MRI, transthoracic echocardiography has inherent limits such as measurement of MPA-d only in parallel and not perpendicular to the direction of the scan plane [27], inadequate images due to chest wall deformities in MFS patients which is reported in 5 to 23 percent [28], and the difficulty to obtain adequate imaging of the pulmonary root.

MPA aneurysms usually occur in the setting of $\mathrm{PH}$, and they have been reported in PH group 1 [29] including $\mathrm{PH}$ related to congenital heart disease [30], where patent ductus arteriosus is the most frequently reported underlying pathology of the MPA aneurysms [31,32], PH group 2, including acquired heart valve disease [20], and $\mathrm{PH}$ group 3 including chronic obstructive pulmonary disease (COPD) [33]. Some MPA aneurysms arise in the absence of $\mathrm{PH}$, and they may have a more benign prognosis than high pressure MPA aneurysms [30,32]. These low pressure MPA aneurysms may arise from pulmonary valve stenosis [20,34], vasculitis such as Behcet's disease [35] or giant cell arteritis [36], infections such as tuberculosis [37], syphilis [38,39] and septic emboli [22], extravascular [40] or endovascular trauma [31,41], or degenerative diseases including atherosclerosis [42] and media degeneration [43]. Some "idiopathic" MPA aneurysms may form without any of these causes $[20,23,44]$.

MPA aneurysms are usually asymptomatic but they may lead to symptoms from right heart failure secondary to pulmonary regurgitation or from compression of the trachea or bronchi, or from pulmonary emboli, which may form in the enlarged MPA [20,31]. MPA dissection is a rare complication of marked MPA aneurysm [21], which is often fatal because it leads to rupture rather than to formation of a re-entry [45].

MPA aneurysms may develop in patients with heritable connective tissue diseases such as Loeys-Dietz syndrome [46,47], and arterial tortuosity syndrome [48], but it is most typically observed in MFS [2-5,49-54]. MFS is an autosomal dominantly inherited disease with a phenotype that involves multiple organ systems and is caused by mutations in the gene coding for fibrillin-1, FBN1. MPA dilatation and aneurysm develop in the absence of common risk factors such as $\mathrm{PH}$, or pulmonary valve or artery stenosis [1]. Instead, it is likely that MPA dilatation and aneurysm develop as a consequence of the weakness of the connective tissue with degeneration of the media layer of the pulmonary vessel similar to the process in the aortic root. As had been pointed out previously, the common embryonic origin of MPA and the aortic root may in part explain the common involvement of both vessels in pathologic processes $[3,55]$, where this common involvement is also the reason why MFS is considered an absolute contraindication for 
usage of the pulmonary root as an autograft in a Ross operation [56,57].

We performed this retrospective cross-sectional observational controlled study with the goal to identify upper normal limits of MPA-d on echocardiography. Moreover, we intended to use these upper normal limits to assess frequency of MPA dilatation, MPA aneurysm, and the need for MPA surgery in adult MFS patients. Finally, we aimed to identify risk factors of MPA dilatation in MFS including specific clinical features of MFS and FBN1 mutation characteristics.

\section{Methods}

\section{Patients}

The study was approved by the Hamburg and the Ghent ethics committee and it was carried out in compliance with the Helsinki Declaration, where patients gave consent to the inclusion into retrospective pseudonymized data analysis. First, we recruited normal individuals aged $\geq 16$ years, with normal results on echocardiography including normal pulmonary artery systolic pressure (PASP) as estimated $<30 \mathrm{mmHg}$ from the tricuspid jet velocity obtained during echocardiographic evaluation [58], to establish normal echocardiographic MPA-d. These individuals underwent cardiovascular evaluation as check-up examinations, as examinations prior to non-cardiovascular operations, or for documentation of cardiovascular health prior to the initiation of medications with potential sideeffects on the cardiovascular system. We excluded persons with a history or current symptoms of cardiovascular disease, lung disease such as COPD, pulmonary embolism, or cardiovascular risk factors comprising diabetes mellitus, chronic arterial hypertension, or with a long-standing history of smoking or current smoking. In this way we identified 73 persons from the University Hamburg-Eppendorf, 18 persons from the Ghent University, 11 persons from the University of Münster, and 21 persons from the University of Lübeck. Thus, echocardiographic recordings of a total of 123 normal persons comprising 72 men and 52 women at a mean age of $42 \pm 14$ years (range 1677 years) were available for uniform assessment of normal MPA-d and MPA-r.

Second, we identified a total of 167 adult inhabitants of the Hamburg metropolitan area [59] with a causative FBN1 gene mutation, who fulfilled diagnostic criteria of MFS according to the current Ghent nosology [9]. Of these 167 patients, we excluded 86 because original echocardiographic recordings were not available, and 5 because we did not perform standardized MPA measurements. Of these remaining 76 patients we excluded 4 other patients, because MPA measurements were technically inadequate (5.2\%). In addition, 26 patients were recruited in Ghent, who were recruited according to the same criteria as in Hamburg [9]. Thus, we identified a total of 98 patients with MFS for this study including 42 men and 56 women at a mean age of $39 \pm 14$ years (range 14-79 years).

\section{Clinical variables}

We obtained age, body weight, body height, at the time of echocardiography, and we calculated body mass index (BMI) and body surface area (BSA) with the formula of $\mathrm{Du}$ Bois [60]. We re-evaluated standard 2-dimensional transthoracic echocardiographic recordings to assess left ventricular (LV) ejection fractions (LVEF) using Simpson's rule [61], and 2-D-targeted M-mode for LV end-systolic (LVESD) and LV end-diastolic diameters (LVEDD) with normalization to BSA, all assessed according to current guidelines [61]. We measured aortic root diameters in the parasternal long-axis view at the level of the aortic sinuses at end-diastole using the leading-edge method as suggested recently (Figure 1, left panel) [62,63] with calculation of Z-scores according to the revised formula of Devereux et al. [64] where we calculated BSA according to Du Bois [60] (Tables 1 and 2).

\section{MPA measurements and definitions}

We measured MPA-d in the parasternal short-axis view at the level of the maximum diameter above the level of the pulmonary root at end-diastole [55] using the leading-edge method (Figure 1, right panel) [65], and we calculated the MPA-r as the ratio of the MPA-d and the aortic root diameter as measured at the level of the aortic sinuses (Figure 1, left panel) [14]. We defined upper normal limits of MPA-d and MPA-r as the 95 quantile of measurements of normal persons. Based on MPA measurements, we defined MPA dilatation as diameters $>$ upper normal limits, MPA aneurysm as diameters $>4 \mathrm{~cm}[20,21]$, and indication for surgery as MPA-d $>6 \mathrm{~cm}$ (Table 3$)[20,21]$.

\section{MFS-related variables}

We considered a family history of MFS in patients with a parent, child or sib who fulfilled diagnostic criteria of MFS. We established ectopia lentis with any unilateral or bilateral displacement of the lenses as documented on slit-lamp examination under full pupillary dilatation [9], or after operation for this entity. We documented pneumothorax with spontaneous pneumothorax on medical records [59], dural ectasia with lumbosacral dural ectasia according to the criteria of Habermann $[66,67]$, striae distensae with striae that were not associated with pronounced weight changes or pregnancy, or with uncommon location such as the mid back, lumbar region, the upper arm, axillary region or thigh as documented during physical examination [9]. We diagnosed myopia with $>-3$ diopters on refractometry during ophthalmic examination or with $>-3$ diopters documented 


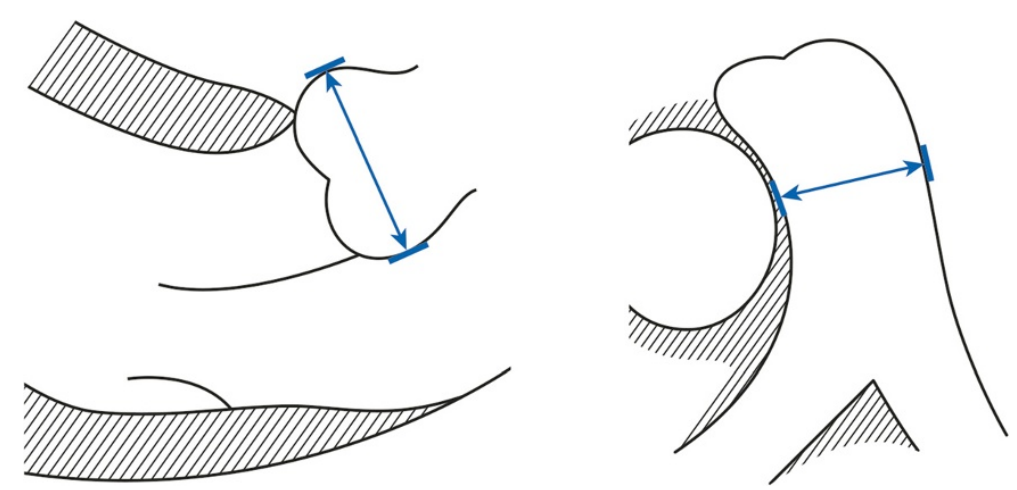

Figure 1 We used 2-dimensional echocardiography to measure both, aortic root diameters and main pulmonary artery (MPA) diameters. We performed all measurements at end-diastole perpendicular to the long axis of the vessel using the leading-edge method. We assessed aortic root diameters in the parasternal long-axis view at the level of the aortic sinuses (left panel) [62], and we measured MPA diameters in the parasternal short-axis view at the level of the maximum diameter above the root of the pulmonary artery (right panel).

on the prescription of spectacles, mitral valve prolapse with posterior or anterior late systolic prolapse on M-mode or on 2-dimensional echocardiography from parasternal long axis views and apical 4-chamber views as leaflet displacement $>2 \mathrm{~mm}$ [68]. We documented a systemic score $\geq 7$ points as defined by revised Ghent criteria [9], where we displayed the score separately for skeletal features comprising the wrist sign, the thumb sign, pectus carinatum, pectus excavatum, chest asymmetry, hindfoot deformity, plain pes planus, protrusio acetabuli, reduced upper segment/lower segment ratio, increased arm/height ratio, scoliosis or thoracolumbar kyphosis, reduced elbow

Table 1 Baseline characteristics

\begin{tabular}{|c|c|c|c|}
\hline Variable & $\begin{array}{l}\text { Normal persons } \\
(N=123)\end{array}$ & $\begin{array}{l}\text { Marfan patients } \\
(\mathrm{N}=98)\end{array}$ & $P^{1}$ \\
\hline Male gender & $72(59 \%)$ & $42(43 \%)$ & .022 \\
\hline Age (years) & $42 \pm 14(16-77)$ & $39 \pm 14(14-79)$ & .113 \\
\hline Body weight (kg) & $75 \pm 14(50-128)$ & $74 \pm 14(45-115)$ & .398 \\
\hline Body height (m) & $1.76 \pm .1(1.51-1.99)$ & $1.85 \pm .1(1.58-2.10)$ & $<.001$ \\
\hline Body mass index $\left(\mathrm{kg} / \mathrm{m}^{2}\right)$ & $24.2 \pm 3.5(16.3-39.9)$ & $21.5 \pm 3.6(15.2-30.8)$ & $<.001$ \\
\hline $\begin{array}{l}\text { Body surface area } \\
\text { (DuBois; } m^{2} \text { ) }\end{array}$ & $1.9 \pm .21(1.51-2.43)$ & $1.96 \pm .21(1.51-2.51)$ & .040 \\
\hline Aortic root diameter $(\mathrm{cm})^{2}$ & $3 \pm .5(1.9-4.2)$ & $4.0 \pm .7(2-5.5)$ & $<.001$ \\
\hline $\begin{array}{l}\text { Z-score of aortic root } \\
\text { diameter }\end{array}$ & $-.8 \pm 1.6(-6.2-1.9)$ & $2.9 \pm 2.3(-4.4-7.4)$ & $<.001$ \\
\hline LV ejection fraction (\%) & $64 \pm 6(55-76)$ & $55 \pm 12(21-78)$ & $<.001$ \\
\hline $\operatorname{LVESD}\left(\mathrm{mm} / \mathrm{m}^{2}\right)$ & $16 \pm 3(9-24)$ & $18 \pm 4(10-36)$ & .005 \\
\hline $\operatorname{LVEDD}\left(\mathrm{mm} / \mathrm{m}^{2}\right)$ & $26 \pm 3(18-32)$ & $27 \pm 5(20-48)$ & .009 \\
\hline $\begin{array}{l}\text { Indexed left atrial diameter } \\
\left(\mathrm{mm} / \mathrm{m}^{2}\right)\end{array}$ & $19 \pm 3(13-27)$ & $19 \pm 5(8-32)$ & .339 \\
\hline \multicolumn{4}{|c|}{$\begin{array}{l}\text { LV identifies left ventricle; LVEDD, indexed left ventricular end-diastolic diameter; } \\
\text { LVESD, indexed left ventricular end-systolic diameter, and MPA ratio, ratio of } \\
\text { main pulmonary artery diameter/aortic root diameter. }{ }^{1} \text { Fisher's exact test for } \\
\text { nominal and categorical data and the Mann-Whitney test for continuous } \\
\text { data. }{ }^{2} \text { We obtained aortic root diameters in } 103 \text { normal persons and in } 76 \\
\text { patients with Marfan syndrome. }\end{array}$} \\
\hline
\end{tabular}

extension, and facial features as the skeletal score, and pneumothorax, skin striae, myopia $>-3$ diopters, and mitral valve prolapse as the non-skeletal score (Table 4) [69].

\section{Molecular analysis}

We amplified all 65 coding exons and intronic flanking splice-sites of FBN1 (NM_000138.4) with polymerase chain reaction (PCR) from genomic deoxyribonucleic acid with previously published primers [70]. Subsequently we purified PCR products and sequenced with a Genetic Analyser (ABI 3130XL, Applied Biosystems Inc., Foster City, CA, USA). We detected gross deletions/duplications in the $F B N 1$ gene with multiplex ligation-dependent probe amplification (MLPA; SALSA ${ }^{\circ}$ MLPA $^{\circ}$ kit, probemix P065 and P066, MRC Holland, Amsterdam, Netherlands). All FBN1 gene nucleotide changes fulfilled $\geq 1$ Ghent criteria of causality as defined by the current Ghent nosology [9].

\section{FBN1 mutation characteristics}

To assess FBN1 mutation characteristics we compared both premature truncation codon-mutations, and splicing mutations versus all other mutations. In mutations with elimination or creation of a cysteine, with location in a calcium binding calcium binding epidermal growth factor-like (cbEGF) domain, or in a latent transforminggrowth-factor beta-binding protein-like (LTBP) domain, or in exons 24-32, we first compared all mutations with the respective characteristic versus all other exon mutations, and second only missense mutations with the respective characteristic versus all other missense mutations (Table 4) [69,71].

\section{Data analysis}

We expressed quantitative data as means \pm standard deviation (range), and qualitative data as numbers (percentage). We compared qualitative data with the Fisher's exact 
Table 2 Correlation $r$ of variables with the diameter of the main pulmonary artery $(\mathrm{cm})$

\begin{tabular}{|c|c|c|c|c|c|c|}
\hline \multirow[b]{3}{*}{ Variable } & \multicolumn{6}{|c|}{ Product-moment correlation coefficient $r(P \text {-value })^{1}$} \\
\hline & \multicolumn{3}{|c|}{ Normal persons } & \multicolumn{3}{|c|}{ Marfan patients } \\
\hline & $\begin{array}{l}\mathrm{All}^{2} \\
(\mathrm{~N}=123)\end{array}$ & $\begin{array}{l}\text { Male } \\
(\mathrm{N}=72)\end{array}$ & $\begin{array}{l}\text { Female } \\
(\mathrm{N}=51)\end{array}$ & $\begin{array}{l}\text { All } \\
(\mathrm{N}=98)\end{array}$ & $\begin{array}{l}\text { Male } \\
(\mathrm{N}=42)\end{array}$ & $\begin{array}{l}\text { Female } \\
(N=56)\end{array}$ \\
\hline Age (years) & $-.095(.296)$ & $-.01(.929)$ & $-.2(.159)$ & $.203(.045)$ & $.279(.074)$ & $.152(.262)$ \\
\hline Body weight (kg) & $.172(.057)$ & $.013(.913)$ & $.293(.037)$ & $.115(.261)$ & $.125(.429)$ & $.133(.327)$ \\
\hline Body height $(\mathrm{m})$ & $.09(.319)$ & $.049(.681)$ & $.145(.311)$ & $.093(.362)$ & $.108(.498)$ & $.130(.340)$ \\
\hline Body mass index $\left(\mathrm{kg} / \mathrm{m}^{2}\right)$ & $.141(.121)$ & $-.036(.766)$ & $.269(.056)$ & $.076(.459)$ & $.096(.543)$ & $.062(.648)$ \\
\hline Body surface area (DuBois; $\mathrm{m}^{2}$ ) & $.149(.099)$ & $.032(.789)$ & $.262(.063)$ & $.120(.240)$ & $.142(.369)$ & $.146(.282)$ \\
\hline
\end{tabular}

${ }^{1} P$-value for rho. ${ }^{2}$ The mean MPA diameters were $2.07 \mathrm{~cm}$ in normal males versus $2.05 \mathrm{~cm}$ in normal females $(P=.747)$.

test and quantitative data with the Mann-Whitney test (Tables 1 and 3). We employed the Shapiro-Wilk W test for normal data and the qnorm plot (Q-Q plot; Figure 2) to test for normal distribution of MPA-d [72], and we assessed the correlation of variables with MPA-d by means of the product-moment correlation coefficient $r$ (Table 2). We used the quantile regression to estimate the 95-quantile and its 95\%-confidence interval. We used the bootstrap technique to get robust estimation of the standard errors. Finally, we examined the relationship of clinical and molecular variables with MPA-d as dependent variable with linear regression analysis (Table 4). We considered $P$-values $<.05$ as significant. We used SPSS software (SPSS for Windows, Release 17.0, SPSS Inc. 1993 to 2007, Chicago, Illinois) and Stata 13 (Stata Statistical Software, Release 13; College Station, TX: StataCorp LP) for statistical analyses.

\section{Results}

Baseline characteristics revealed less females $(P=.022)$, smaller body-height, BSA $(P=.040)$, aortic root diameters, aortic Z-scores (all $P<.001)$, indexed LVESD $(P=.005)$ and

Table 3 Two-dimensional echocardiographic findings of the main pulmonary artery (MPA)

\begin{tabular}{|c|c|c|c|}
\hline Variable & $\begin{array}{l}\text { Normal persons } \\
(\mathrm{N}=123)\end{array}$ & $\begin{array}{l}\text { Marfan patients } \\
(\mathrm{N}=98)\end{array}$ & $P^{1}$ \\
\hline MPA diameter (cm) & $2.1 \pm .3(1.1-3.1)$ & $3.1 \pm .7(1.9-4.7)$ & $<.001$ \\
\hline $\begin{array}{l}\text { MPA dilatation } \\
\text { (diameter }>2.6 \mathrm{~cm} \text { ) }\end{array}$ & $6(4.9 \%)$ & $68(69.4 \%)$ & $<.001$ \\
\hline $\begin{array}{l}\text { MPA aneurysm } \\
\text { (diameter }>4.0 \mathrm{~cm} \text { ) }\end{array}$ & 0 & $15(15.3 \%)$ & $<.001$ \\
\hline MPA diameter $>6.0 \mathrm{~cm}$ & 0 & 0 & \\
\hline$\overline{M P A}$ ratio ${ }^{2}$ & $.7 \pm .19(.3-1.2)$ & $.8 \pm .21(.5-1.5)$ & .001 \\
\hline MPA ratio $>1.05^{2}$ & $6(5.8 \%)$ & $8(10.5 \%)$ & .161 \\
\hline
\end{tabular}

LV identifies left ventricular; LVEDD, indexed left ventricular end-diastolic diameter; LVESD, indexed left ventricular end-systolic diameter, and MPA ratio, ratio of main pulmonary artery diameter/aortic root diameter. ${ }^{1}$ Fisher's exact test for nominal and categorical data and the Mann-Whitney test for continuous data. ${ }^{2}$ We obtained aortic root diameters in 103 normal persons and in 76 patients with Marfan syndrome. indexed LVEDD $(P=.009)$ and higher BMI and LVEF (both $P<.001$ ) in normal adults than in MFS (Table 1 ).

MPA-d revealed normal distribution (Figure 2; $P=.133$ ) without correlation to age, body weight, body height, BMI and BSA both in normal adults and in MFS and with equal distribution of MPA diameters in men and women $(P=.747$; Table 2). The mean MPA-d in normal adults was $2.1 \mathrm{~cm}(95 \%$ confidence interval $(\mathrm{CI})=2.00-2.12 \mathrm{~cm})$, and the upper normal limit of MPA-d was $2.6 \mathrm{~cm}(95 \%$ $\mathrm{CI}=2.44-2.76 \mathrm{~cm})$. The mean MPA-r in normal adults was $.70(95 \% \mathrm{CI}=.67-.74)$, and the upper limit of normal MPA-r was $1.05(95 \% \mathrm{CI}=.86-1.24)$.

With $2.1 \pm .3$ versus $3.1 \pm .7(P<.001)$, and with $.71 \pm .19$ versus $.8 \pm .31(P<.001)$, both MPA-d and MPA-r were smaller in normal persons than in MFS. MPA dilatation was present in 6 normal persons (4.9\%) and in 68 MFS (69.4\%; $P<.001)$, MPA aneurysm was diagnosed only in MFS (15 patients; $15.3 \%$; $P<.001$; Figure 3 , upper panel), but no patient required surgery of MPA aneurysm. Using our threshold $>1.05$, MPA-r were increased in 6 normal persons (5.8\%) and in 8 MFS patients $(10.5 \%$; $P=.161$; Table 3; Figure 3, lower panel).

Finally, linear regression analysis identified a relationship of increased MPA-d with increased aortic root diameters (regression coefficient $(b)=.308 ; 95 \%$ CI .011-.604; $P=.042)$, with reduced LVEF $(b=-.021 ; 95 \%$ $\mathrm{CI}=-.036-.006 ; P=.006)$, with increased indexed LVEDD $(\mathrm{b}=.043 ; 95 \% \mathrm{CI}=-.007-.079 ; P=.021)$, and with increased PASP $(b=.023 ; 95 \% \mathrm{CI}=.001-.045 ; P=.040)$. Conversely, no clinical manifestation of MFS, and no FBN1 mutation characteristic related to MPA-d (Table 4).

\section{Discussion}

Our study yielded five major results. First, we identified echocardiographic MPA-d $>2.6 \mathrm{~cm}$ as upper normal limit of normal adults independent of age, sex, body height, body weight, BMI and BSA. Second, adults with MFS exhibited MPA dilatation in 69.4\%, and MPA aneurysm in $15.3 \%$, where no patient fulfilled criteria for surgical intervention. Third, MPA-r were increased in 
Table 4 Relationship of variables with MPA diameter in 72 Marfan patients ${ }^{1}$

\begin{tabular}{llll}
\hline Clinical variables & $\begin{array}{l}\text { Regression } \\
\text { coefficient (b) }\end{array}$ & $\begin{array}{l}\text { 95\% confidence } \\
\text { interval }\end{array}$ & $\boldsymbol{P}^{2}$ \\
\hline Aortic root dilatation & -.118 & $-.491-.225$ & .531 \\
\hline Previous aortic root surgery & -.054 & $-.449-.342$ & .787 \\
\hline Aortic root diameter (cm) & .308 & $.011-.604$ & .042 \\
\hline Z-score of aortic root diameter & .035 & $-.051-.122$ & .414 \\
\hline LV ejection fraction (\%) & -.021 & $-.036-.006$ & .006 \\
\hline LVESD (mm/m $\left.{ }^{2}\right)$ & .024 & $-.018-.065$ & .258 \\
\hline LVEDD (mm/m $\left.{ }^{2}\right)$ & .043 & $-.007-.079$ & .021 \\
\hline PASP (mmHg) & .023 & $.001-.045$ & .040 \\
\hline Family history of Marfan & .132 & $-.217-.482$ & .452 \\
\hline Ectopia lentis & -.183 & $-.531-.165$ & .298 \\
\hline Pneumothorax & -.133 & $-.617-.351$ & .585 \\
\hline Dural ectasia (Habermann) & .095 & $-.254-.443$ & .590 \\
\hline Striae distensae & -.021 & $-.331-.373$ & .906 \\
\hline Myopia > -3 diopters & -.294 & $-.691-.102$ & .143 \\
\hline Mitral valve prolapse & .224 & $-.427--.020$ & .081 \\
\hline Systemic score $\geq 7$ points & -.026 & $-.415-.364$ & .895 \\
\hline - Total systemic score points & -.010 & $-.076-.054$ & .764 \\
\hline - Skeletal score points & -.030 & $-.113-.053$ & .470 \\
\hline - Non-skeletal score points & .033 & $-.095-.161$ & .610 \\
\hline FBN1 mutation characteristics & & & \\
\hline PTC mutations & -.150 & $-.550-.249$ & .455 \\
\hline Splicing mutations & .208 & $-.422-.837$ & .513 \\
\hline Any mutation affecting Cys & .027 & $-.359-.412$ & .890 \\
\hline Missense affecting Cys & -.026 & $-.536-.484$ & .919 \\
\hline Any mutation in cbEGF & -.133 & $-.365-.262$ & .589 \\
\hline Missense in cbEGF & -.021 & $-.564-.606$ & .943 \\
\hline Any mutation in LTBP-bd & -.540 & $-1.240-.160$ & .128 \\
\hline Missense mutation in LTBP-bd & .018 & $-1.106-1.142$ & .974 \\
\hline Any mutation in exons 24-32 & -.135 & $-.643-.373$ & .597 \\
\hline Missense in exons 24-32 & -.014 & $-.654-.629$ & .965 \\
\hline bEGF indefis & & \\
\hline
\end{tabular}

cbEGF indetifies calcium-binding epidermal growth factor-like domain; coefficient, regression coefficient; Cys, cysteine; LV, left ventricular; LVEDD, indexed left ventricular end-diastolic diameter, LVESD, indexed left ventricular end-systolic diameter, LTBP-bd, latent TGF-beta-binding domain; missense, missense mutation; $\mathrm{N}$, number; PASP, pulmonary artery systolic pressure; and PTC, premature termination codon. 'We analyzed on those 72 patients, whom we recruited in Hamburg. ${ }^{2}$ Linear regression analysis. ${ }^{2}$ PASP measurements were $22 \pm 12 \mathrm{mmHg}$ (range $6-49 \mathrm{mmHg}$ ).

MFS as compared to normal persons, where a ratio $>1.05$ was identified as the upper normal limit. Fourth, MPA-d are similar in normal persons and MFS and may thus not be useful as diagnostic markers of MPA dilatation in MFS. Finally, MPA-d increased with PASP, aortic root diameters, reduced LVEF, dilated LVEDD but MPA-d did not relate to manifestations of MFS or to FBN1 mutation characteristics.

In normal adults, upper limits of MPA-d were only defined on CT and MRI, where limits ranged between
$2.8 \mathrm{~cm} \mathrm{[4],} 2.96 \mathrm{~cm}$ [13], $3.01 \mathrm{~cm} \mathrm{[14],} \mathrm{and} 3.24 \mathrm{~cm}$ [15]. Our echocardiographic limit of $2.6 \mathrm{~cm}$ was slightly lower most likely because measurements on tomographic studies are usually obtained as outer diameters of a vessel rather than with the leading-edge method $[25,26]$. Our threshold may also be because some studies did not exclude PH $[4,14,18]$. Moreover, echocardiography measures MPA-d at other sites than on CT or MRI [2]. Most importantly, upper limits of MPA-d were defined differently as $90^{\text {th }}$ percentile [14], as $95^{\text {th }}$ percentile [13], or as diameters $0.5 \mathrm{~mm}$ above the maximum diameter [4]. One study used the maximum diameters measured in normal persons as upper normal limit of MPA-d [15]. Similarly, De Backer et al. identified $2.3 \mathrm{~cm}$ as cut-off of normal limit MPA-d on echocardiography, but they employed receiver operating characteristic curve analysis to separate normal persons from MFS rather than that they defined upper normal limits of MPA-d [2].

Using $2.6 \mathrm{~cm}$ as threshold we identified a high prevalence of MPA dilatation in MFS. One MRI study of 86 MFS patients listed different cut off values for MPA diameters [3], and used various methods to assess MPA dilatation: According to the old Ghent criteria for assessment of MPA dilatation [1], where a nomogram of the aorta made by Roman et al. [62] was employed to assess MPA dilatation, none of the patients were found to have dilatation of the MPA, and only seven patients had dilatation of the root of the pulmonary artery. Conversely, when using the cut off $\geq 3.0 \mathrm{~cm}$ as proposed by Bozlar et al. [13], the same authors found that $54 \%$ of MFS patients had MPA dilatation. Another study identified $76 \%$ of 50 MFS patients using $2.8 \mathrm{~cm}$ at the level of the bifurcation as threshold for MPA dilatation [4]. Interestingly, those two MRI studies with similar cut-off values as in our study identify MPA dilatation in $76 \%$ [4] and $54 \%$ of MFS [3] which was similar to our $69.4 \%$.

We identify MPA aneurysms in 19\% of MFS patients. The single study in the literature that also assesses the prevalence of MPA aneurysm in MFS reports an even higher frequency of 4 in 11 adults with MFS (36.4\%) [73]. However, we did not identify any patient who required surgery for MPA-d $>6.0 \mathrm{~cm}$, or with complications such as regurgitation of the pulmonary valve, MPA dissection, or upper airway compression. In the series of Detrano et al. there was a single patient in 11 adults with MFS who exhibited an MPA-d $>6.0 \mathrm{~cm}(9 \%)$ [73]. There is only casuistic evidence for complications of MPA aneurysm in MFS [49,50,52]. Interestingly, the Framingham Heart Study noted self-reported dyspnoea on exertion in $20 \%$ of normal persons with MPA-d above upper normal limits [14]. We did not assess symptoms in our MFS patients, but in summary there is little evidence 


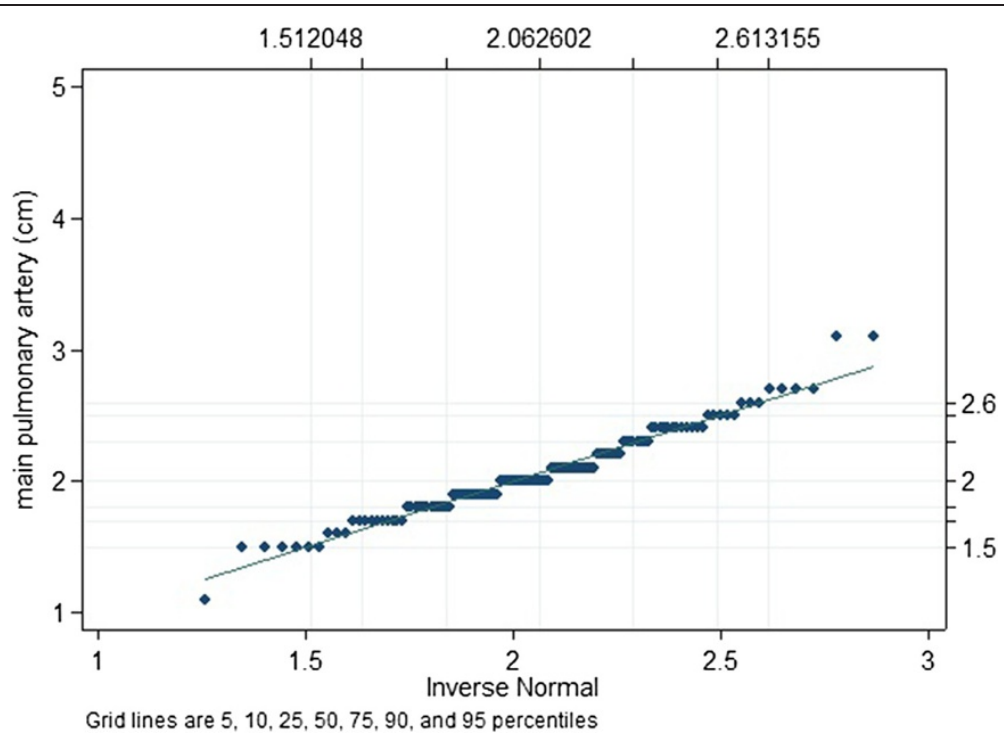

Figure 2 The qnorm (Q-Q plot) plots the quantiles of MPA diameters $(\mathrm{cm})$ of 123 normal adults against the quantiles of a normal distribution where the pattern of points in the plot is used to compare these two distributions. The plot identifies normal distribution with only a slight deviation from normality at the upper tail. The Shapiro-Wilk W test for normal data corroborates normal distribution of MPA diameters yielding $W=0.98330, V=1.641, z=1.111$, and $P=.133$.

that MPA aneurysm are a frequent source of complications in MFS.

The Framingham Heart Study defined their normal cohort of 706 persons similar to our criteria as individuals without obesity, arterial hypertension, current and past smokers, chronic obstructive pulmonary disease, history of pulmonary embolism, diabetics, cardiovascular disease, and heart valve surgery [14]. The study corroborated our finding that body height, body weight, BMI and BSA were not needed to define normal upper limits of MPA-d. We also did not identify significant sex-specific differences of MPA-d, whereas the Framingham study was the only study to define cut-off values for women and men. However, their normal population consisted of men aged $>35$, and women aged $>40$ years [14], whereas our normal population included much younger persons of both sexes. Moreover, studies with similar age distribution as in our study corroborated lack of significant differences between both sexes $[13,19]$.

Our study defined $>1.05$ as upper normal limit of MPA-r on echocardiography, and thus corroborated thresholds form CT or MRI studies [16-19]. However, it is important to note that we measured aortic diameters at the level of the aortic sinuses, whereas MRI studies obtained aortic diameters as transverse axial diameters of the ascending aorta. Interestingly, with $>0.9$ the Framingham study reported an unusually low upper normal limit of MPA-r. But again, the Framingham study included only persons aged $>35$ years, and MPA-r is known to decrease with age, because only the proximal aorta dilates with older age [19]. Because of its age dependency, MPA-r is considered only of limited value for diagnosing $\mathrm{PH}[19]$.

We found MPA-r $>1.05$ with similar frequency in normal persons $(5 \%)$ and in MFS (10.5\%). This finding may be conceived as "pseudo-normal" MPA-r in MFS, where dilatation of MPA is neutralized by dilatation of the aortic root. Hence, MPA-r is not a good marker of MPA dilatation in MFS. However, we found a relationship of MPA-r with PASP in our MFS patients (regression coefficient (b) $=.009 ; 95 \%$ CI .000-.017; $P=.047$ ), and hence, increased MPA-r may be useful to identify PH with increased risk for MPA aneurysm in MFS.

We identified a relationship of MPA dilatation with reduced LVEF, dilated LVEDD [74,75] and with increased PASP in MFS. Hence, MFS patients may develop highpressure MPA aneurysm [52] when pulmonary hypertension develops from decreases of their myocardial function. Such decreases of myocardial function frequently develop in MFS from regurgitation of the aortic or mitral valve [76] or after repeated heart surgery $[77,78]$.

Manifestations of MFS result from weakness of the tissue. Hence, it appears surprising that MPA-d did not relate to any other manifestations of MFS such as ectopia lentis, pneumothorax, dural ectasia, striae distensae, marked myopia, mitral valve prolapse, or Ghent scores of system involvement. A possible explanation is that additional factors are needed to manifest MPA dilatation. The association of enlarged MPA-d with increased PASP may 


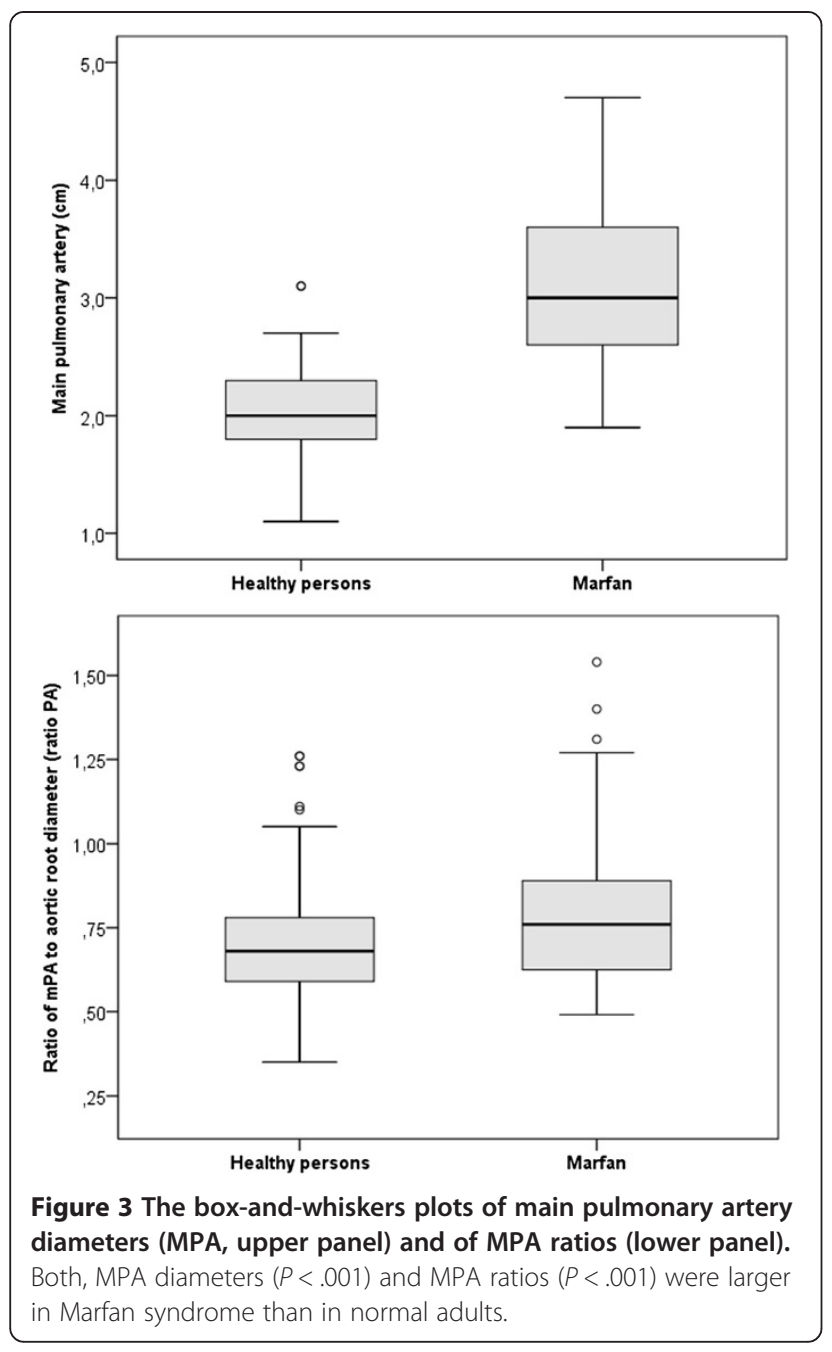

indicate that $\mathrm{PH}$ is required as an additional factor to manifest formation of marked MPA aneurysm in MFS.

With FBN1 mutations located in exons 24-32 MFS exhibits both, more pronounced aortic root disease [71] and more frequent ventricular arrhythmia events [7]. However, we did not identify a relationship of FBN1 mutation characteristics with increased MPA-d. This finding supports the idea that MPA dilatation is driven by factors, which may not relate directly of the underlying disease mechanisms of MFS.

\section{Study limits}

Some issues of our study may need discussion for appropriate estimation of our findings. First, our study provides normal echocardiographic values of MPA-d for adults, which can be used in any clinical setting independently of MFS. However, larger populations may be needed to corroborate our normative thresholds. Second, our MFS patients were sampled retrospectively with selection for availability of original echocardiographic recordings.
Third, echocardiography may not be optimal for measuring MPA-d in adults, because diameters of the arterial walls are parallel to the direction of the scan plane and may thus not be measured precisely [27], or measurements may be inadequate as found in $5.3 \%$ of our MFS patients, and in $4 \%$ of MFS patients reported by De Backer et al. [2]. However, a recently published quality review of echocardiographic measurements found that intraobserver agreements for aortic root and MPA measurements were excellent [79]. Moreover, we did not include measurements of the pulmonary root because these were too variable both between the same observer and between different observers. Fourth, the levels and techniques of echocardiographic MPA measurements are not universally defined and hence our data may not be comparable with measurements in the literature. Fifth, we estimated PASP from non-invasive echocardiography without validation through right-heart catheterization [58]. Finally, our crosssectional study was retrospective with reevaluation of routine echocardiographic examinations, where prospective longitudinal studies with standardized echocardiographic protocols may be needed to evolve the natural history of MPA dilatation in MFS.

\section{Conclusions}

We establish $2.6 \mathrm{~cm}$ as upper normal value of echocardiographic MPA-d and 1.05 for MPA-r. In MFS, the prevalence of MPA dilatation is $69.4 \%$ and the prevalence of MPA aneurysm is $15.3 \%$. However, patients may require MPA surgery only in scarce circumstances, most likely because formation of marked MPA aneurysm may require LV dysfunction and increased PASP.

\section{Abbreviations \\ BMI: Body mass index; BSA: Body surface area; cbEGF: Calcium binding calcium binding epidermal growth factor-like domain; COPD: Chronic obstructive pulmonary disease; CT: Computed tomography; FBN1: Fibrillin-1 gene; LVEF: Left ventricular ejection fraction; LVEDD: Left ventricular end- diastolic diameter; LVESD: Left ventricular end-systolic diameter; LTBP: Latent transforming-growth-factor beta-binding protein-like domain; MFS: Marfan syndrome; MPA: Main pulmonary artery; MPA-d: MPA diameter; MPA-r: MPA ratio; MRI: Magnetic resonance imaging; PASP: Pulmonary artery systolic pressure; PH: Pulmonary hypertension; Q-Q plot: Qnorm plot.}

\section{Competing interests}

All authors declare that they have no competing interests.

\section{Authors' contributions}

$\mathrm{SS}, \mathrm{JDB}, \mathrm{MR}, \mathrm{MH}, \mathrm{HS}, \mathrm{DK}, \mathrm{AMB}, \mathrm{KM}$, and RMR recruited and evaluated normal normal persons, SS, JDB, NRG, MR, MH, HS, AMB, DK, PB, TSM, and TK examined Marfan patients and contributed to the assessment of clinical data; BK and JS performed sequencing and analysis of molecular data. JB and YVK performed the statistical analysis; YVK evaluated the data and wrote the manuscript. All authors discussed the design of the study and revised the manuscript. All authors read and approved the final manuscript.

\section{Author details}

${ }^{1}$ Centre of Cardiology and Cardiovascular Surgery, University Medical Center Hamburg-Eppendorf, Martinistraße 52, 20246 Hamburg, Germany.

${ }^{2}$ Department of Diagnostic and Interventional Radiology, University Hospital Eppendorf, Hamburg, Germany. ${ }^{3}$ Department of Medical Biometry and 
Epidemiology, University Hospital Eppendorf, Hamburg, Germany. ${ }^{4}$ Centre for Medical Genetics, University Hospital Ghent, Ghent, Belgium. ${ }^{5}$ Institute of Human Genetics, Hannover Medical School, Hannover, Germany.

${ }^{6}$ Medizinische Klinik II / Kardiologie, Angiologie, am Universitätsklinikum Schleswig-Holstein, Campus Lübeck, Germany. ${ }^{7}$ Department für Kardiologie und Angiologie, Universitätsklinikum Münster, Münster, Germany. ${ }^{8}$ Institute of Medical Genetics, Charité Universitätsmedizin Berlin, Berlin, Germany.

Received: 9 July 2014 Accepted: 26 November 2014

Published online: 10 December 2014

\section{References}

1. De Paepe A, Devereux RB, Dietz HC, Hennekam RC, Pyeritz RE: Revised diagnostic criteria for the Marfan syndrome. Am J Med Genet 1996, 62:417-426.

2. De Backer J, Loeys B, Devos D, Dietz H, De Sutter J, De Paepe A: A critical analysis of minor cardiovascular criteria in the diagnostic evaluation of patients with Marfan syndrome. Genet Med 2006, 8:401-408.

3. Lundby R, Rand-Hendriksen S, Hald JK, Pripp AH, Smith HJ: The pulmonary artery in patients with Marfan syndrome: a cross-sectional study. Genet Med 2012, 14:922-927.

4. Nollen GJ, van Schijndel KE, Timmermans J, Groenink M, Barentsz JO, van der Wall EE, Stoker J, Mulder BJ: Pulmonary artery root dilatation in Marfan syndrome: quantitative assessment of an unknown criterion. Heart 2002, 87:470-471.

5. Nollen GJ, van Schijndel KE, Timmermans J, Groenink M, Barentsz JO, van der Wall EE, Stoker J, Mulder BJ: Magnetic resonance imaging of the main pulmonary artery: reliable assessment of dimensions in Marfan patients on a simple axial spin echo image. Int J Cardiovasc Imaging 2003, 19:141-147. discussion 149-150.

6. Murdoch JL, Walker BA, Halpern BL, Kuzma JW, McKusick VA: Life expectancy and causes of death in the Marfan syndrome. N Engl Med 1972, 286:804-808.

7. Aydin A, Adsay BA, Sheikhzadeh S, Keyser B, Rybczynski M, Sondermann C, Detter C, Steven D, Robinson PN, Berger J, Schmidtke J, Blankenberg S, Willems $S$, von Kodolitsch Y, Hoffmann BA: Observational cohort study of ventricular arrhythmia in adults with marfan syndrome caused byFBN1 mutations. PLoS One 2013, 8(12):e81281.

8. Hoffmann BA, Rybczynski M, Rostock T, Servatius H, Drewitz I, Steven D, Aydin A, Sheikhzadeh S, Darko V, von Kodolitsch Y, Willems S: Prospective risk stratification of sudden cardiac death in Marfan's syndrome. Int J Cardiol 2013, 167:2539-2545.

9. Loeys BL, Dietz HC, Braverman AC, Callewaert BL, De Backer J, Devereux RB, Hilhorst-Hofstee Y, Jondeau G, Faivre L, Milewicz DM, Pyeritz RE, Sponseller PD, Wordsworth P, De Paepe AM: The revised Ghent nosology for the Marfan syndrome. J Med Genet 2010, 47:476-485.

10. Pati PK, George PV, Jose JV: Giant pulmonary artery aneurysm with dissection in a case of marfan syndrome. J Am Coll Cardiol 2013, 61:685-685.

11. Nollen GJ, Mulder BJ: What is new in the Marfan syndrome? Int J Cardiol 2004, 97(Suppl 1):103-108.

12. Sohn GH, Jang SY, Moon JR, Yang JH, Sung K, Ki CS, Oh JK, Choe YH, Kim DK: The usefulness of multidetector computed tomographic angiography for the diagnosis of Marfan syndrome by Ghent criteria. Int J Cardiovasc Imaging 2011, 27:679-688.

13. Bozlar U, Ors F, Deniz O, Uzun M, Gumus S, Ugurel MS, Yazar F, Tayfun C Pulmonary artery diameters measured by multidetector-row computed tomography in healthy adults. Acta Radiol 2007, 48(10):1086-1091.

14. Truong QA, Massaro JM, Rogers IS, Mahabadi AA, Kriegel MF, Fox CS, O'Donnell CJ, Hoffmann U: Reference values for normal pulmonary artery dimensions by noncontrast cardiac computed tomography: the Framingham Heart Study. Circ Cardiovasc Imaging 2012, 5:147-154.

15. Karazincir S, Balci A, Seyfeli E, Akoglu S, Babayigit C, Akgul F, Yalcin F, Egilmez E: CT assessment of main pulmonary artery diameter. Diagn Interv Radiol 2008, 14:72-74

16. Ng CS, Wells AU, Padley SP: A CT sign of chronic pulmonary arterial hypertension: the ratio of main pulmonary artery to aortic diameter. J Thorac Imaging 1999, 14:270-278.

17. Kuriyama K, Gamsu G, Stern RG, Cann CE, Herfkens RJ, Brundage BH: CT-determined pulmonary artery diameters in predicting pulmonary hypertension. Investig Radiol 1984, 19:16-22.
18. Edwards PD, Bull RK, Coulden R: CT measurement of main pulmonary artery diameter. Br J Radiol 1998, 71:1018-1020.

19. Lin FY, Devereux RB, Roman MJ, Meng J, Jow VM, Simprini L, Jacobs A, Weinsaft JW, Shaw LJ, Berman DS, Callister TQ, Min JK: The right sided great vessels by cardiac multidetector computed tomography: normative reference values among healthy adults free of cardiopulmonary disease, hypertension, and obesity. Acad Radiol 2009, 16:981-987.

20. Tuncer A, Tuncer EY, Tas SG, Erdem H, Polat A: Repair of pulmonary artery aneurysms. J Card Surg 2011, 26:501-505.

21. Theodoropoulos P, Ziganshin BA, Tranquilli M, Elefteriades JA: Pulmonary artery aneurysms: Four case reports and literature review. Int $J$ Angiol 2013, 22:143-148

22. Deterling RA Jr, Clagett OT: Aneurysm of the pulmonary artery; review of the literature and report of a case. Am Heart J 1947, 34:471-499.

23. Deb SJ, Zehr KJ, Shields RC: Idiopathic pulmonary artery aneurysm. Ann Thorac Surg 2005, 80:1500-1502.

24. Elefteriades JA, Farkas EA: Thoracic aortic aneurysm clinically pertinent controversies and uncertainties. J Am Coll Cardiol 2010, 55:841-857.

25. Shimada I, Rooney SJ, Pagano D, Farneti PA, Davies P, Guest PJ, Bonser RS Prediction of thoracic aortic aneurysm expansion: validation of formulae describing growth. Ann Thorac Surg 1999, 67:1968-1970. discussion 1979-1980.

26. Groth M, Henes FO, Bannas P, Muellerleile K, Adam G, Regier M: Intraindividual comparison of contrast-enhanced MRI and unenhanced SSFP sequences of stenotic and non-stenotic pulmonary artery diameters. Röfo 2011, 183:47-53.

27. Weymann A: Principles and Practice of Echocardiography. Second editionth edition. Philadelphia: Lippincott Williams \& Wilkins; 1994.

28. von Kodolitsch Y, Rybczynski M: Cardiovascular Aspects of the Marfan Syndrome A Systematic Review. New York: Kluwer Academic / Plenum Publishers; 2004.

29. Simonneau G, Gatzoulis MA, Adatia I, Celermajer D, Denton C, Ghofrani A, Gomez Sanchez MA, Krishna Kumar R, Landzberg M, Machado RF, Olschewski H, Robbins IM, Souza R: Updated clinical classification of pulmonary hypertension. J Am Coll Cardiol 2013, 62:D34-D41.

30. Fakler U, Mebus S, Kaemmerer H, Will A, Eicken A, Weiss M, Reichard B, Hess J: A ticking time bomb-high pressure pulmonary artery aneurysm. Am J Med 2008, 121:777-780

31. Butto F, Lucas RV Jr, Edwards JE: Pulmonary arterial aneurysm. A pathologic study of five cases. Chest 1987, 91:237-241.

32. Veldtman GR, Dearani JA, Warnes CA: Low pressure giant pulmonary artery aneurysms in the adult: natural history and management strategies. Heart 2003, 89:1067-1070.

33. Khattar RS, Fox DJ, Alty JE, Arora A: Pulmonary artery dissection: an emerging cardiovascular complication in surviving patients with chronic pulmonary hypertension. Heart 2005, 91:142-145.

34. Tami LF, McElderry MW: Pulmonary artery aneurysm due to severe congenital pulmonic stenosis. Case report and literature review. Angiology 1994, 45:383-390.

35. Tunaci M, Ozkorkmaz B, Tunaci A, Gul A, Engin G, Acunas B: CT findings of pulmonary artery aneurysms during treatment for Behcet's disease. AJR Am J Roentgenol 1999, 172:729-733.

36. Dennison AR, Watkins RM, Gunning AJ: Simultaneous aortic and pulmonary artery aneurysms due to giant cell arteritis. Thorax 1985, 40:156-157.

37. Keeling AN, Costello R, Lee MJ: Rasmussen's aneurysm: a forgotten entity? Cardiovasc Intervent Radiol 2008, 31:196-200.

38. Tulpule MR, Advani DG, Gulati RB, Patki SA, Dumbre RB: Syphilitic disease of pulmonary artery. Indian Heart J 1982, 34:260-261.

39. Donnell JJ, Levinson DC, Griffith GC: Clinical studies on involvement of the pulmonary artery by syphilitic aortic aneurysms. Circulation 1956, 13:75-81.

40. DiNardo JA: Traumatic pseudoaneurysm of a pulmonary artery: anesthetic considerations. Anesthesiology 1986, 65:334-338.

41. Boyd KD, Thomas SJ, Gold J, Boyd AD: A prospective study of complications of pulmonary artery catheterizations in 500 consecutive patients. Chest 1983, 84:245-249.

42. Navas Lobato MA, Martin Reyes R, Luruena Lobo P, Mate Benito I, Guzman Hernandez G, Marti de Gracia M, Sobrino Daza JA, Lopez Sendon JL: Pulmonary artery dissection and conservative medical management. Int I Cardiol 2007, 119:e25-e26.

43. Shilkin KB, Low LP, Chen BT: Dissecting aneurysm of the pulmonary artery. J Pathol 1969, 98:25-29.

44. Ring NJ, Marshall AJ: Idiopathic dilatation of the pulmonary artery. $\mathrm{Br} J$ Radiol 2002, 75:532-535. 
45. Senbaklavaci $O$, Kaneko $Y$, Bartunek A, Brunner $C$, Kurkciyan E, Wunderbaldinger $P$, Klepetko W, Wolner E, Mohl W: Rupture and dissection in pulmonary artery aneurysms: incidence, cause, and treatment-review and case report. J Thorac Cardiovasc Surg 2001, 121:1006-1008.

46. Muramatsu Y, Kosho T, Magota M, Yokotsuka T, Ito M, Yasuda A, Kito O, Suzuki C, Nagata Y, Kawai S, Ikoma M, Hatano T, Nakayama M, Kawamura R, Wakui K, Morisaki H, Morisaki T, Fukushima Y: Progressive aortic root and pulmonary artery aneurysms in a neonate with Loeys-Dietz syndrome type 1B. Am J Med Genet A 2010, 152A:417-421.

47. Kuppler KM, Kirse DJ, Thompson JT, Haldeman-Englert CR: Loeys-Dietz syndrome presenting as respiratory distress due to pulmonary artery dilation. Am J Med Genet A 2012, 158A:1212-1215.

48. Al-Khaldi A, Mohammed Y, Tamimi O, Alharbi A: Early outcomes of total pulmonary arterial reconstruction in patients with arterial tortuosity syndrome. Ann Thorac Surg 2011, 92:698-704. discussion 704

49. Anderson M, Pratt-Thomas HR: Marfan's syndrome. Am Heart J 1953, 46:911-917.

50. Disler LJ, Manga P, Barlow JB: Pulmonary arterial aneurysms in Marfan's syndrome. Int J Cardiol 1988, 21:79-82.

51. Ramaswamy P, Lytrivi ID, Nguyen K, Gelb BD: Neonatal Marfan syndrome: in utero presentation with aortic and pulmonary artery dilatation and successful repair of an acute flail mitral valve leaflet in infancy. Pediatr Cardiol 2006, 27:763-765.

52. Bowden DH, Favara BE, Donahoe JL: Marfan's syndrome: Accelerated course in childhood associated with lesions of mitral valve and pulmonary artery. Am Heart J 1965, 69:96-99.

53. Song EK, Kolecki P: A case of pulmonary artery dissection diagnosed in the Emergency Department. J Emerg Med 2002, 23:155-159.

54. Ting P, Jugdutt BI, Le Tan J: Large pulmonary artery aneurysm associated with Marfan syndrome. Int J Angiol 2010, 19:e48-e50.

55. Kutty S, Kaul S, Danford CJ, Danford DA: Main pulmonary artery dilation in association with congenital bicuspid aortic valve in the absence of pulmonary valve abnormality. Heart 2010, 96:1756-1761.

56. Joyce F, Tingleff J, Pettersson G: Expanding indications for the Ross operation. J Heart Valve Dis 1995, 4:352-363.

57. Sievers HH, Hanke T, Stierle U, Bechtel MF, Graf B, Robinson DR, Ross DN: A critical reappraisal of the Ross operation: renaissance of the subcoronary implantation technique? Circulation 2006, 114:|504-1511.

58. Galie N, Manes A, Branzi A: Evaluation of pulmonary arterial hypertension. Curr Opin Cardiol 2004, 19:575-581.

59. Rybczynski M, Bernhardt AM, Rehder U, Fuisting B, Meiss L, Voss U, Habermann C, Detter C, Robinson PN, Arslan-Kirchner M, Schmidtke J, Mir TS, Berger J, Meinertz T, von Kodolitsch Y: The spectrum of syndromes and manifestations in individuals screened for suspected Marfan syndrome. Am J Med Genet A 2008, 146A:3157-3166.

60. Du Bois D, Du Bois EF: A formula to estimate the approximate surface area if height and weight be known. 1916. Nutrition 1989, 5:303-311. discussion 312-303.

61. Lang RM, Bierig M, Devereux RB, Flachskampf FA, Foster E, Pellikka PA Picard MH, Roman MJ, Seward J, Shanewise J, Solomon S, Spencer KT, St John Sutton M, Stewart W: Recommendations for chamber quantification. Eur J Echocardiogr 2006, 7:79-108.

62. Roman MJ, Devereux RB, Kramer-Fox R, O'Loughlin J: Two-dimensional echocardiographic aortic root dimensions in normal children and adults. Am J Cardiol 1989, 64:507-512.

63. Lang RM, Bierig M, Devereux RB, Flachskampf FA, Foster E, Pellikka PA, Picard MH, Roman MJ, Seward J, Shanewise JS, Solomon SD, Spencer KT, Sutton MS, Stewart WJ: Recommendations for chamber quantification: a report from the American Society of Echocardiography's Guidelines and Standards Committee and the Chamber Quantification Writing Group, developed in conjunction with the European Association of Echocardiography, a branch of the European Society of Cardiology. J Am Soc Echocardiogr 2005, 18:1440-1463.

64. Devereux RB, de Simone G, Arnett DK, Best LG, Boerwinkle E, Howard BV, Kitzman D, Lee ET, Mosley TH Jr, Weder A, Roman MJ: Normal limits in relation to age, body size and gender of two-dimensional echocardiographic aortic root dimensions in persons $>/=15$ years of age. Am J Cardiol 2012, 110:1189-1194.

65. Snider AR, Enderlein MA, Teitel DF, Juster RP: Two-dimensional echocardiographic determination of aortic and pulmonary artery sizes from infancy to adulthood in normal subjects. Am J Cardiol 1984, 53:218-224.
66. Habermann CR, Weiss F, Schoder V, Cramer MC, Kemper J, Wittkugel O, Adam G: MR evaluation of dural ectasia in Marfan syndrome: reassessment of the established criteria in children, adolescents, and young adults. Radiology 2005, 234:535-541.

67. Sheikhzadeh S, Sondermann C, Rybczynski M, Habermann CR, Brockstaedt L, Keyser B, Kaemmerer H, Mir T, Staebler A, Robinson PN, Kutsche K, Berger J, Blankenberg S, von Kodolitsch Y: Comprehensive analysis of dural ectasia in 150 patients with a causative FBN1 mutation. Clin Genet 2014, 86:238-245.

68. Freed LA, Levy D, Levine RA, Larson MG, Evans JC, Fuller DL, Lehman B, Benjamin EJ: Prevalence and clinical outcome of mitral-valve prolapse. N Engl J Med 1999, 341:1-7.

69. Sheikhzadeh S, Kade C, Keyser B, Stuhrmann M, Arslan-Kirchner M, Rybczynski M, Bernhardt AM, Habermann CR, Hillebrand M, Mir T, Robinson PN, Berger J, Detter C, Blankenberg S, Schmidtke J, von Kodolitsch Y: Analysis of phenotype and genotype information for the diagnosis of Marfan syndrome. Clin Genet 2012, 82:240-247.

70. Nijbroek G, Sood S, Mclntosh I, Francomano CA, Bull E, Pereira L, Ramirez F, Pyeritz RE, Dietz HC: Fifteen novel FBN1 mutations causing Marfan syndrome detected by heteroduplex analysis of genomic amplicons. Am J Hum Genet 1995, 57:8-21.

71. Faivre L, Collod-Beroud G, Loeys BL, Child A, Binquet C, Gautier E, Callewaert B, Arbustini E, Mayer K, Arslan-Kirchner M, Kiotsekoglou A, Comeglio P, Marziliano N, Dietz HC, Halliday D, Beroud C, Bonithon-Kopp C, Claustres M, Muti C, Plauchu H, Robinson PN, Ades LC, Biggin A, Benetts B, Brett M, Holman KJ, De Backer J, Coucke P, Francke U, De Paepe A, et al.: Effect of mutation type and location on clinical outcome in 1,013 probands with Marfan syndrome or related phenotypes and FBN1 mutations: an international study. Am J Hum Genet 2007, 81:454-466.

72. Shapiro SS, Wilk MB: Analysis of variance test for normality (complete samples). Biometrika 1965, 52:591-611.

73. Detrano R, Moodie DS, Gill CC, Markovich D, Simpfendorfer C: Intravenous digital subtraction aortography in the preoperative and postoperative evaluation of Marfan's aortic disease. Chest 1985, 88:249-253.

74. De Backer JF, Devos D, Segers P, Matthys D, Francois K, Gillebert TC, De Paepe AM, De Sutter J: Primary impairment of left ventricular function in Marfan syndrome. Int J Cardiol 2006, 112:353-358.

75. Rybczynski M, Koschyk DH, Aydin MA, Robinson PN, Brinken T, Franzen O, Berger J, Hofmann T, Meinertz T, von Kodolitsch Y: Tissue Doppler imaging identifies myocardial dysfunction in adults with Marfan syndrome. Clin Cardiol 2007, 30:19-24

76. Rybczynski M, Mir TS, Sheikhzadeh S, Bernhardt AM, Schad C, Treede H, Veldhoen S, Groene EF, Kuhne K, Koschyk D, Robinson PN, Berger J, Reichenspurner $\mathrm{H}$, Meinertz T, von Kodolitsch Y: Frequency and agerelated course of mitral valve dysfunction in the Marfan syndrome. Am J Cardiol 2010, 106:1048-1053.

77. Kiotsekoglou A, Sutherland GR, Moggridge JC, Nassiri DK, Camm J, Child AH: The unravelling of primary myocardial impairment in Marfan syndrome by modern echocardiography. Heart 2009, 95:1561-1566.

78. Knosalla C, Weng YG, Hammerschmidt R, Pasic M, Schmitt-Knosalla I, Grauhan O, Dandel M, Lehmkuhl HB, Hetzer R: Orthotopic heart transplantation in patients with Marfan syndrome. Ann Thorac Surg 2007, 83:1691-1695.

79. Selamet Tierney ES, Levine JC, Chen S, Bradley TJ, Pearson GD, Colan SD, Sleeper LA, Campbell MJ, Cohen MS, De Backer J, Guey LT, Heydarian H, Lai WW, Lewin MB, Marcus E, Mart CR, Pignatelli RH, Printz BF, Sharkey AM, Shirali GS, Srivastava S, Lacro RV: Echocardiographic methods, quality review, and measurement accuracy in a randomized multicenter clinical trial of Marfan syndrome. J Am Soc Echocardiogr 2013, 26:657-666.

doi:10.1186/s13023-014-0203-8

Cite this article as: Sheikhzadeh et al: The main pulmonary artery in adults: a controlled multicenter study with assessment of echocardiographic reference values, and the frequency of dilatation and aneurysm in Marfan syndrome. Orphanet Journal of Rare Diseases 2014 9:203. 